\title{
The Independent Evolution of Dorsal Pallia in Multiple Vertebrate Lineages
}

\author{
Georg F. Striedter ${ }^{a}$ R. Glenn Northcutt ${ }^{b}$ \\ ${ }^{a}$ Department of Neurobiology and Behavior, University of California Irvine, Irvine, CA, USA; ${ }^{b}$ Scripps Institution of \\ Oceanography and Department of Neurosciences, School of Medicine, University of California San Diego, La Jolla, \\ CA, USA
}

\section{Keywords}

Neocortex · Pallium · Evolution · Olfaction · Lamprey

\begin{abstract}
Comparative neurobiologists have long wondered when and how the dorsal pallium (e.g., mammalian neocortex) evolved. For the last 50 years, the most widely accepted answer has been that this structure was already present in the earliest vertebrates and, therefore, homologous between the major vertebrate lineages. One challenge for this hypothesis is that the olfactory bulbs project throughout most of the pallium in the most basal vertebrate lineages (notably lampreys, hagfishes, and lungfishes) but do not project to the putative dorsal pallia in teleosts, cartilaginous fishes, and amniotes (i.e., reptiles, birds, and mammals). To make sense of these data, one may hypothesize that a dorsal pallium existed in the earliest vertebrates and received extensive olfactory input, which was subsequently lost in several lineages. However, the dorsal pallium is notoriously difficult to delineate in many vertebrates, and its homology between the various lineages is often based on little more than its topology. Therefore, we suspect that dorsal pallia evolved independently in teleosts, cartilaginous fishes, and amniotes. We fur-
\end{abstract}

ther hypothesize that the emergence of these dorsal pallia was accompanied by the phylogenetic restriction of olfactory projections to the pallium and the expansion of inputs from other sensory modalities. We do not deny that the earliest vertebrates may have possessed nonolfactory sensory inputs to some parts of the pallium, but such projections alone do not define a dorsal pallium.

(C) 2021 The Author(s)

Published by S. Karger AG, Basel

The two of us recently wrote a book called Brains Through Time: A Natural History of Vertebrates [Striedter and Northcutt, 2020] in which we reviewed diverse aspects of vertebrate evolution with a focus on the nervous system. Among the evolutionary changes we discussed are major transformations of the telencephalon, especially the so-called pallium, which in mammals consists of the pallial septum, the hippocampal and parahippocampal cortices, the neocortex, the claustroinsular cortex, the olfactory cortex, and part of the amygdala. Of particular interest over the years has been the question of when and how the dorsal pallium - generally known as the neocortex in mammals - emerged during phylogeny. As we researched this topic for our book, we concluded that a dor-
(C) 2021 The Author(s)

Published by S. Karger AG, Basel

This is an Open Access article licensed under the Creative Commons Attribution-NonCommercial-4.0 International License (CC BY-NC) (http://www.karger.com/Services/OpenAccessLicense), applicable to the online version of the article only. Usage and distribution for commercial purposes requires written permission.
Correspondence to:

Georg F. Striedter, georg.striedter@gmail.com 
sal pallium probably evolved several times independently. Specifically, we proposed that it evolved in the lineage leading to amniotes (i.e., reptiles, birds, and mammals), in the lineage leading to ray-finned fishes, and in cartilaginous fishes. Because of the general neurobiological importance of this issue, we here present a tightly focused account of the arguments that led to this conclusion. We also offer a few additional considerations, especially regarding recent findings in lampreys. We begin with a philosophical preamble and a brief history of the problem.

\section{Similarities or Differences: Which Deserve More Attention?}

Our book was explicitly focused on the "key innovations" of the major vertebrate lineages, exploring how these novelties relate to one another and contributed to each lineage's ecological and evolutionary success. Given this focus, it was natural for us to emphasize species differences rather than conserved features. Extracting those differences from the published literature was not always easy, because many authors either eschew comparative analyses or emphasize the similarities between major taxa. Indeed, a focus on species similarities is common in many areas of biology, where the use of diverse species as "models" is a major research strategy [Bolker, 2019; Striedter, 2019]. Moreover, it seems to us that discoveries of unexpected conservation are easier to publish - especially in high-profile journals - than reports of features that are unique to specific lineages, unless the lineage includes humans. After all, conservation is relatively simple to explain as the result of "inheritance from a common ancestor." In contrast, lineage-specific features require more complex explanations that, ideally, reference both developmental mechanisms and functional correlates.

Because we think that species similarities already receive plenty of attention in many areas of biology, including the comparative neurobiological literature, we felt justified in adopting a somewhat contrarian focus on species differences. That said, the recognition of species similarities is clearly an important exercise. As Francis Bacon wrote in 1620: "The greatest and, perhaps, radical distinction between different men's dispositions for philosophy and the sciences is this, that some are more vigorous and active in observing the differences of things, others in observing their resemblances ... each of them readily falls into excess" [cited in Friedmann, 2004].

Evolution of Dorsal Pallia
We wholeheartedly agree but add that science and scientists tend to go through phases in which the discovery of similarities is paramount, followed by periods where interest in differences is more useful. Generally speaking, when humans are confronted with a profusion of seemingly disparate data, it is natural for them to seek patterns, which are usually grounded in similarities. Once those patterns are identified, deviations become discernible, which then prompts another round of pattern detection. As David Bohm [1957] observed, it is this tension between order and disorder - between similarities and differences - that drives scientific advance. In short, our emphasis on species differences should not be misconstrued as advocating for chaos. Instead, we are interested in identifying species differences that stand out against a background of conserved features.

\section{Previous Ideas about Pallial Evolution}

The term pallium has long been used to describe the dorsocaudal part of the telencephalon in vertebrates. Some authors use cortex instead of pallium, but the latter term is preferable because, even in mammals, some pallial regions do not exhibit the layered organization that the cortex label generally implies. Especially in embryonic brains the pallium is recognizable at stages that exhibit no cortical layering, even in mammals.

The pallium itself has long been recognized as consisting of several divisions. The medial pallium is generally thought to develop into the hippocampus and some immediately adjacent structures, whereas the lateral pallium was traditionally regarded as olfactory cortex. In between the medial and lateral pallia, most investigators have recognized a dorsal pallium (aka general pallium) but, until the late 1960s, this pallial division was thought to arise relatively late in vertebrate phylogeny, specifically in the lineage leading to amniotes. This is why the principal derivative of the embryonic dorsal pallium in mammals is called the neocortex; it was thought to be relatively new.

Although the hippocampus in amniotes does not receive major direct projections from the olfactory bulbs (i.e., secondary olfactory projections), early comparative neuroanatomists thought that the medial pallium in anamniotes (i.e., vertebrates other than amniotes) does receive at least some secondary olfactory projections. Given that the lateral pallium also receives major inputs from the olfactory bulb, as well as the aforementioned belief that anamniotes lack a dorsal pallium, these early

Brain Behav Evol 2021;96:200-211 
neuroanatomists concluded that the entire pallium of anamniotes is dominated by olfactory inputs. This idea came to be known as the "smell brain hypothesis" of pallial evolution. According to this theory, it was only with the emergence of the dorsal pallium in amniotes that olfactory projections to the pallium became more limited and were displaced by inputs from other sensory modalities.

These early views were upended in the late 1960s and 1970s, when new neuroanatomical tracing techniques revealed that the secondary olfactory projections in sharks and teleost fishes (e.g., goldfish) were restricted to relatively small portions of the pallium and that some of the remaining nonolfactory regions receive inputs from other sensory modalities [Ebbesson and Heimer, 1970; Scalia and Ebbesson, 1971; Northcutt, 1981]. These observations suggested that a dorsal pallium must have evolved long before amniotes appeared. Thus emerged a general consensus that all vertebrates (or at least all jawed vertebrates) have a tripartite pallium comprising medial, dorsal, and lateral pallia [e.g., Butler and Hodos, 2005]. A few authors noted that a fourth pallial division, corresponding to pallial portions of the amygdala, might exist between the lateral pallium and the subpallium [Northcutt, 1981, 1995], but this idea for many years received relatively little attention.

This situation changed in the late 1990s, when Fernandez et al. [1998] reported that the transcription factor Emxl is expressed throughout most of the pallium in amphibians and amniotes but is absent from the most ventral portion of the lateral pallium. Puelles et al. [2000] recognized the importance of this finding and identified the Emx1-negative zone as a fourth principal division of the pallium, which they named ventral pallium. Later studies showed that this ventral pallium selectively expresses Dbx1 [Medina et al., 2004] and, in mammals, gives rise to most of the olfactory cortex, parts of the amygdala, and the ventral endopiriform nucleus [Puelles et al., 2016]. There has been a long-running debate about the extent of this ventral pallium in reptiles and birds, where it appears to be greatly enlarged [Striedter, 1997; Puelles, 2017; Puelles et al., 2017; Wullimann, 2017b]. More important for present purposes is that this tetrapartite model of pallial organization is now widely considered to apply across all vertebrates, with the possible exception of cyclostomes (see below). If this is true, then a dorsal pallium should exist in all jawed vertebrates and be homologous between them [Northcutt, 1995; Butler and Hodos, 2005].

\section{Chinks in the Paradigm}

As we were preparing our book, we were forced to confront 2 observations that do not fit comfortably into the currently dominant view of pallial evolution. Specifically, we had to deal with the fact that: (1) the secondary olfactory projections in several anamniotes reportedly target most or all of the pallium and (2) the dorsal pallium in these anamniotes is difficult, if not impossible, to delineate with certainty. In response, we began to reconsider the smell brain hypothesis and questioned some dorsal pallium homologies.

\section{The Smell Brain Hypothesis Revisited}

Beginning in the 1980s, experimental neuroanatomical studies revealed that the secondary olfactory projections are surprisingly extensive in several anamniotes. Specifically, Northcutt and Puzdrowski [1988] showed that the olfactory bulbs in lampreys project to most of the pallium, a finding that was corroborated by Polenova and Vesselkin [1993] in a second lamprey species. Wicht and Northcutt [1993; 1998] reported analogous results for hagfishes, and Northcutt and Rink [2012] did the same for lungfishes. Given that cyclostomes (i.e., lampreys and hagfishes) as well as lungfishes are the sister groups of jawed vertebrates and tetrapods, respectively (Fig. 1), these findings suggest that widespread olfactory projections to the pallium might have been the primitive condition for vertebrates, just as the smell brain hypothesis had posited. Under this scenario, the secondary olfactory projections would have become more restricted in several vertebrate lineages, notably amniotes, ray-finned fishes, and cartilaginous fishes (Fig. 1). Alternatively, the secondary olfactory projections may have been restricted to just part of the pallium in the earliest vertebrates and later expanded in multiple lineages.

To decide between these 2 hypotheses, we considered additional data from amphibians, in which the olfactory bulb projects to the entire lateral pallial wall, including the so-called dorsal pallium, but not to most of the medial pallium [Northcutt and Royce, 1975; Neary, 1990] (Fig. 2). This pattern is intermediate between that of lungfishes (with their widely distributed olfactory projections) and the highly restricted olfactory projections in amniotes, which is interesting because amphibians are also phylogenetically intermediate between lungfishes and amniotes (Fig. 1). Comparative morphologists refer to such a pattern of orderly intermediate traits in intermediate taxa as a morphocline [Maslin, 1952]. Importantly, these data support the hypothesis that the second- 
Fig. 1. Convergent restriction of secondary olfactory projections to the pallium. Shown here are the vertebrate taxa discussed in the text and their phylogenetic relationships. The circles represent the pallium, and the shaded portion represents the extent to which the olfactory bulbs project to the principal pallial zones; they are most widespread in cyclostomes and lungfishes and most restricted in elasmobranchs, teleosts, and amniotes. Also shown are the hypothesized character states at ancestral nodes and the discussed transformations (arrows).

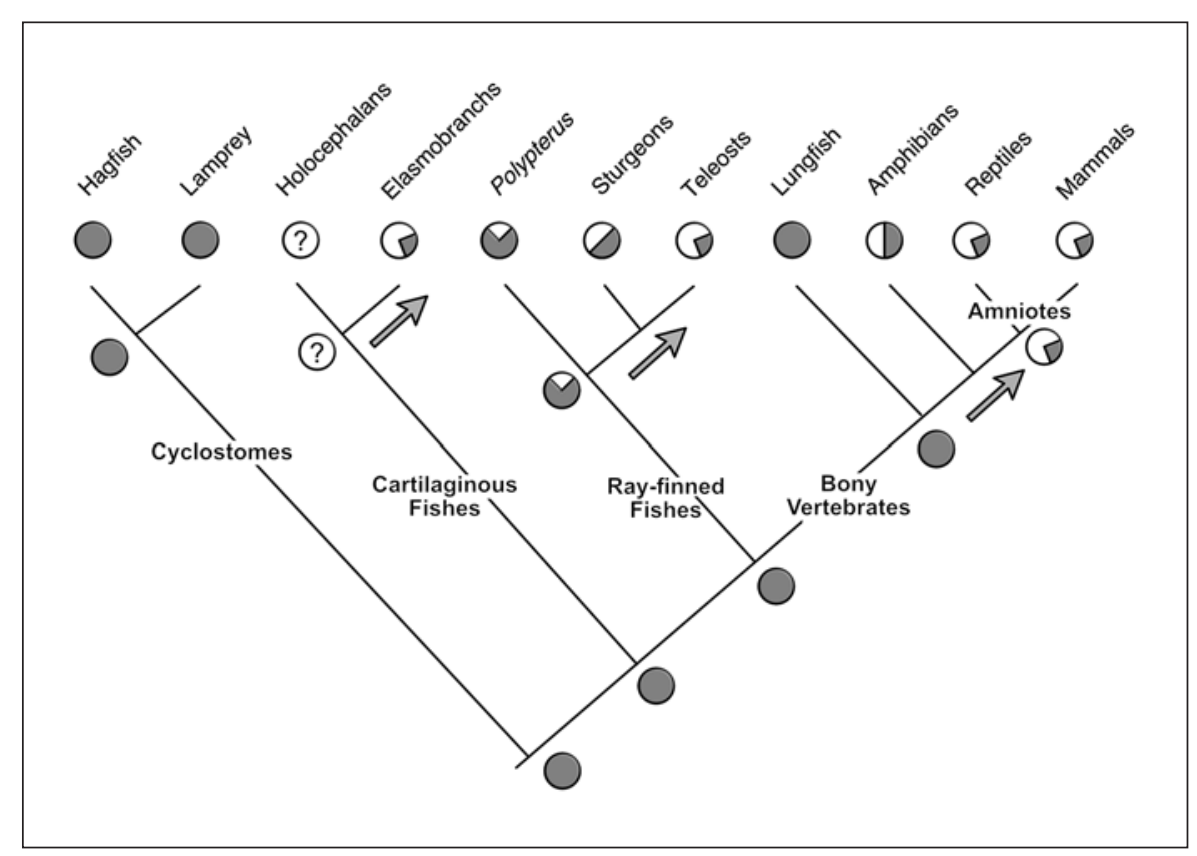

ary olfactory projections became progressively more restricted along the lineage leading to amniotes. An analogous set of studies on ray-finned fishes [Northcutt and Davis, 1983; von Bartheld and Meyer, 1986; Northcutt, 2011] shows that the secondary olfactory projections are most extensive in the most basal lineage (i.e., Polypterus) and become progressively more restricted in the more derived lineages, notably teleosts (Fig. 2). Please note that we here use "basal" and "derived" to denote lineages that originated from more and less ancient nodes in the phylogenetic tree, respectively. Since our basal lineages contain few species, we evade the problems otherwise associated with identifying basal lineages [Krell and Cranston, 2004].

Based on these considerations, we endorse the hypothesis that the olfactory bulbs of early vertebrates projected throughout the pallium and that those projections became more restricted in several vertebrate lineages. In short, we think that the smell brain hypothesis was discarded prematurely and that its core idea - of the earliest vertebrates having an olfaction-dominated pallium - deserves to be resurrected. We acknowledge that some pallial neurons in the earliest vertebrates may well have received ascending inputs from other sensory modalities, but we hypothesize that these neurons also received olfactory inputs. One can debate whether the existence of such nonolfactory inputs to the pallium would falsify the original smell brain hypothesis entirely [Wullimann, 2017a], or just its most extreme version, but this is not our concern here.

\section{A Dorsal Pallium Identity Crisis}

Because the dorsal pallium in amniotes is associated with nonolfactory sensory (e.g., visual and somatosensory) processing, our embrace of the smell brain hypothesis prompted us to question whether early anamniotes had a dorsal pallium. Specifically, we wondered whether they might have possessed a dorsal pallium that, in contrast to the dorsal pallium of amniotes, received secondary olfactory projections, which were subsequently lost. This hypothesis would be strengthened if extant anamniotes all had dorsal pallia that are very similar in other respects and, thus, likely to be homologous across anamniotes.

However, the existing literature on the putative dorsal pallia of anamniotes is rife with debates and uncertainties. For example, different authors have described very different boundaries for the supposed dorsal pallium of amphibians, and we currently suspect that what most researchers (including us) have previously called the dorsal pallium in amphibians is merely a transition zone between the medial and lateral pallia. It remains possible that amphibians do possess a small dorsal pallium that forms an island between the medial and lateral pallia and is apparent only at a few rostrocaudal levels [Nerea Moreno García, pers. commun.; see also Puelles, 2001], but positive evidence for this hypothesis has not been pub- 
lished. Similarly, a dorsal pallium has been reported to exist in lungfishes [González and Northcutt, 2009; Northcutt, 2009], but this region is poorly differentiated from the lateral pallium and may, therefore, be a dorsal portion of the lateral pallium rather than a distinct primary pallial zone.

A dorsal pallium remains elusive also in Polypterus. This basal ray-finned fish does have a large pallium with several subdivisions, but a thorough analysis by Holmes and Northcutt [2003] suggested that the Polypterus pallium consists of only 2 large divisions, each of which contains 2 subdivisions. The medial subdivision of the dorsolateral division does not receive inputs from the olfactory bulb [von Bartheld and Meyer, 1986] (Fig. 2) and is therefore a potential homolog of the dorsal pallium in amniotes, but (in contrast to the dorsal pallium of amniotes) it does not receive thalamic input and is poorly delineated from its lateral neighbor; thus, it is a dubious dorsal pallium candidate. Other ray-finned fishes, notably teleosts, possess a more distinct structure that may be called a dorsal pallium [Mueller et al., 2011], but how this region relates to the pallial divisions of Polypterus remains unclear (see The Ray-Finned Fish Revolution).

The situation is even more confusing in cyclostomes. Hagfishes have a large and complex pallium that is so different from the pallium of other vertebrates that homologizing its divisions is fraught with uncertainties [Wicht and Northcutt, 1992, 1993, 1998]. The pallium of lampreys is much smaller and simpler, but whether it contains a dorsal pallium homologous to that of amniotes has long been a matter of debate (see The Lamprey Conundrum).

In short, the structures that have previously been identified as dorsal pallia in anamniotes with relatively widespread secondary olfactory projections tend to be small and poorly differentiated or (perhaps) absent entirely. This observation, in turn, suggests that dorsal palliumlike structures may well have evolved independently in the lineages in which the secondary olfactory projections became more restricted [Wullimann and Vernier, 2009]. Some of the strongest evidence in support of this hypothesis comes from ray-finned fishes.

\section{The Ray-Finned Fish Revolution}

The ray-finned fishes comprise roughly half of all vertebrates and are enormously diverse; so is their pallium. Whereas the pallium of Polypterus is rather simple, that of teleost fishes is complex, especially in large-brained

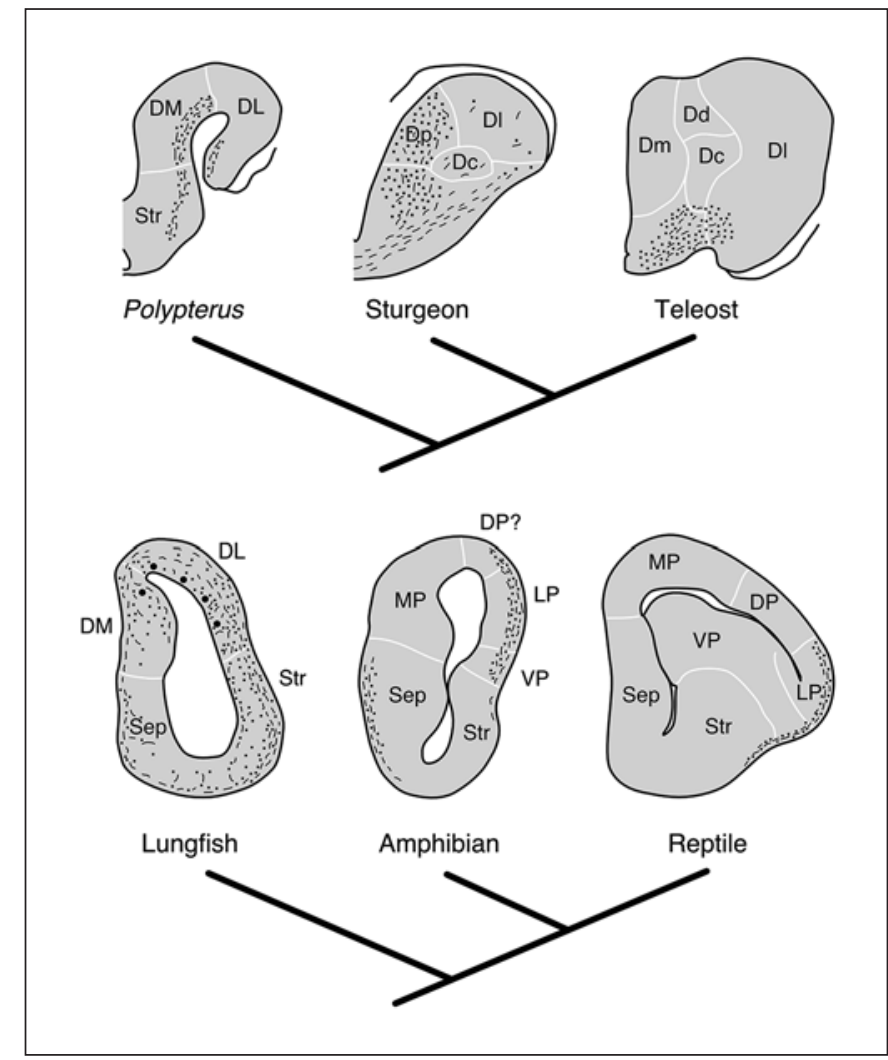

Fig. 2. Two similar but independent morphoclines of pallial organization. Shown here are sections through the right telencephalon of 3 ray-finned fishes (top) and 3 bony vertebrates (bottom). Axons and terminals labeled after tracer injections into the main olfactory bulb are indicated schematically. In both instances, the olfactory projections to the pallium become progressively more restricted from left to right, forming 2 independent morphoclines. Similarly, evidence for the existence of distinct dorsal pallia (Dd plus Dc in teleosts and DP in reptiles) increases from left to right. Dc, central part of area dorsalis; Dd, dorsal part of area dorsalis; $\mathrm{Dl}$, lateral part of area dorsalis; DL, dorsolateral pallium; Dm, medial part of area dorsalis; DM, dorsomedial pallium; Dp, posterior part of area dorsalis (replaced by Dm anteriorly); DP, dorsal pallium; LP, lateral pallium; MP, medial pallium; Sep, septum; Str, striatum; VP, ventral pallium. Adapted from Striedter and Northcutt [2000] and sources cited therein, as well as in this text.

teleosts [Braford, 2009; Harvey-Girard et al., 2012; Demski, 2013]. This complexity makes it difficult to compare the various pallial divisions of teleosts to those of other vertebrates - a problem that is compounded by the fact that the telencephalon of ray-finned fishes is everted rather than evaginated (Fig. 2) [Nieuwenhuys, 2009]. For these reasons, the various divisions of the teleostean telencephalon were wisely named according to their topological position, rather than putative homologies [Nieu- 
wenhuys, 1963; Northcutt and Braford, 1980]. Undaunted, researchers have nonetheless proposed a number of hypotheses concerning the homologies of pallial divisions in teleosts. Particularly important for present purposes is that the dorsal and central parts of the dorsal telencephalon (Dd and Dc) have been identified as plausible candidates for homologs of the dorsal pallium in other vertebrates [Wullimann and Mueller, 2004; Mueller et al., 2011; Porter and Mueller, 2020].

A significant problem with this hypothesis is that Dd, which is small and indistinct in most teleosts, appears to be absent in Polypterus as well as sturgeons, which are another basal lineage of ray-finned fishes (Fig. 2). Sturgeons do possess a small cluster of large neurons that resembles area Dc of teleosts, but no such region is evident in the Polypterus pallium [Northcutt and Davis, 1983]. A large part of Dc in teleosts has strong projections to the optic tectum [Murakami et al., 1983], but numerous tracer injections into the tectum of Polypterus revealed no retrogradely labeled pallial cells (unpublished observations by RGN). Thus, we here observe a morphocline across the major lineages of ray-finned fishes that is consistent with Dd and Dc emerging gradually in the lineage leading to teleosts. If this is true, then Dd and Dc cannot be homologous to the dorsal pallium of other vertebrates, since the traditional definition of homology (to which we subscribe) requires that homologs share a continuous phylogenetic history since their origin in a common ancestor [Striedter and Northcutt, 1991].

In conjunction with the emergence of $\mathrm{Dd}$ and $\mathrm{Dc}$, the pallium of ray-finned fishes became less dominated by olfactory input (Fig. 2) and, in teleosts, came to process sensory information from a variety of sensory modalities, including vision, taste, and lateral line stimuli. However, these nonolfactory sensory regions are mainly located in the lateral and medial parts of the dorsal telencephalon (Dl and Dm; see Fig. 2) [Murakami et al., 1983; Kanwal et al., 1988; Striedter, 1991; von der Emde and Prechtl, 1999; Saidel et al., 2001; Yamamoto and Ito, 2008; Demski, 2013; Ocaña et al., 2016], which are usually homologized to the medial pallium and ventral pallium of other vertebrates, respectively [Rodríguez et al., 2002; Braford, 2009; Nieuwenhuys, 2009]. Furthermore, these pallial regions in teleosts receive their sensory inputs not from the thalamus but from a complex set of structures - called the preglomerular complex - that is derived from the posterior basal diencephalon and midbrain [Bloch et al., 2020; Wullimann, 2020]. Given these data, it is most parsimonious to hypothesize that teleosts evolved a variety of novel pallial features, including $\mathrm{Dd}$, long descending pro- jections from Dc, and nonolfactory sensory regions in other pallial divisions. All of these innovations are superficially similar to features of the dorsal pallium in amniotes, but they almost certainly evolved convergently.

\section{Those Pesky Elasmobranchs}

The cartilaginous fishes comprise holocephalans (e.g., ratfishes) and a much larger lineage called elasmobranchs (i.e., sharks, skates, and rays), but experimental neurobiological data are currently available only for the latter group. Importantly, the data from elasmobranchs pose a significant challenge to our proposed model of dorsal pallial evolution, because the secondary olfactory projections in these animals are restricted to a relatively small lateral portion of the pallium [Ebbesson and Heimer, 1970; Hofmann and Northcutt, 2008; Striedter and Northcutt, 2020]. Moreover, responses to visual and electrosensory stimuli have been recorded in some of the nonolfactory pallial regions, including the medial pallium and the so-called dorsal pallium [Ebbesson and Schroeder, 1971; Bodznick and Northcutt, 1984; Bodznick, 1990]. Whether this nonolfactory sensory information is conveyed to the pallium of elasmobranchs via the thalamus or other brain regions, or both, remains debated in the literature [Luiten, 1981; Smeets and Northcutt, 1987; Hofmann and Northcutt, 2012; Wullimann and Grothe, 2013], and higher-order olfactory projections do appear to dominate the telencephalon in at least some elasmobranchs [Hofmann and Northcutt, 2008]. However, the available data are certainly consistent with the notion that cartilaginous fishes possess a region that is similar to the dorsal pallium of amniotes insofar as it lacks secondary olfactory inputs and is targeted by other ascending sensory pathways.

Since cartilaginous fishes are the sister group of bony vertebrates (including ray-finned fishes, lungfishes, and amniotes; see Fig. 1), these data weaken support for the smell brain hypothesis. However, considering the morphoclines mentioned above, it is still slightly more parsimonious to assume that widespread secondary olfactory projections are primitive for vertebrates and became restricted in elasmobranchs than to suggest that they evolved independently in cyclostomes and early bony fishes. Whether the dorsal pallium of elasmobranchs evolved independently from that in other vertebrates is similarly uncertain, but it is interesting to note that the region identified as the dorsal pallium in elasmobranchs became disproportionately large and complex in several lineages of 
Fig. 3. Features of a lamprey's pallium. The top 2 transverse sections depict axons, terminals, and cell bodies labeled after tracer injections in the olfactory bulb (a) and dorsal thalamus (b). c Axons and cell bodies retrogradely labeled in the rostral (left) and more caudal (right) telencephalon after tracer injections in the pretectum (which likely interrupted axons projecting to the optic tectum as well). d Location of neurons that respond to electrical stimulation of the retina; several principal dendrites for one of these neurons are also shown. Adapted from Northcutt and Puzdrowski [1988], Northcutt and Wicht [1997], Ocaña et al. [2015], and Suryanarayana et al. [2020].

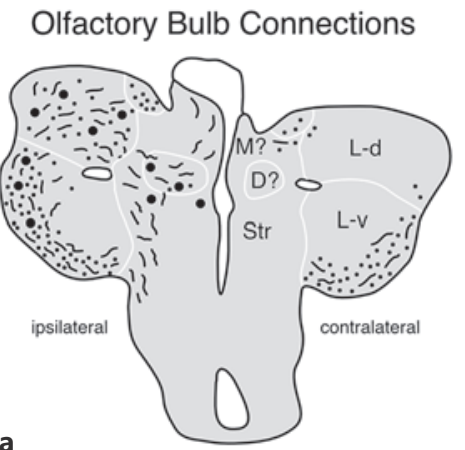

a

Long Descending Connections

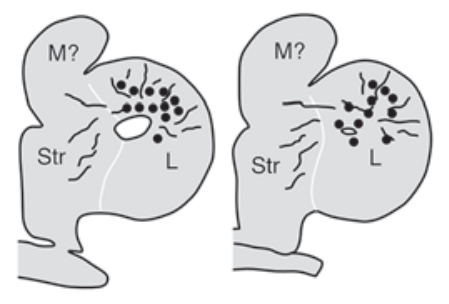

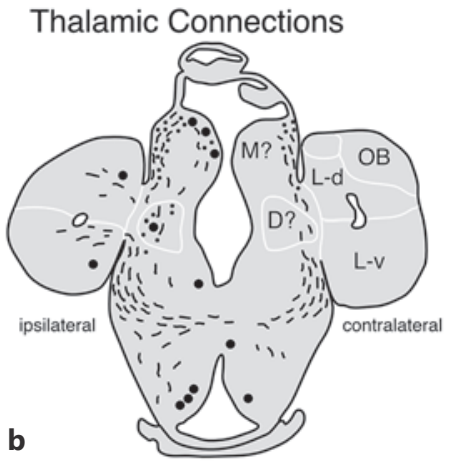

Responsive to Retinal Stimuli

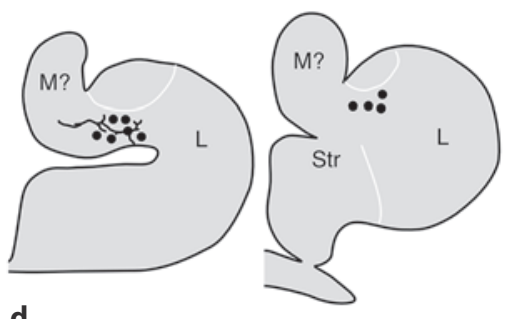

c

large-brained sharks and rays that emerged relatively recently during elasmobranch phylogeny [Northcutt, 1995]. All of these data make us extremely curious about pallial organization in holocephalans (the sister group of all elasmobranchs). On the basis of cytoarchitectural analysis, these animals are said to have a relatively complex dorsal pallium [Smeets et al., 2011], but in our judgement this region could be a well-developed medial pallium [Striedter and Northcutt, 2020]. Unfortunately, this idea remains speculative, as no experimental studies on the telencephalon of holocephalans have been published.

Overall, we suspect that the secondary olfactory projections became more restricted early in the evolution of cartilaginous fishes and that this restriction was associated with the origin and subsequent expansion of a dorsal pallium that is not homologous to the dorsal pallia of teleosts or amniotes. However, this hypothesis is probably the weakest link in our general model.

\section{The Lamprey Conundrum}

The pallium of lampreys has long been difficult to interpret. Part of the problem is that the secondary olfactory projections in these animals are so widespread
[Northcutt and Puzdrowski, 1988; Polenova and Vesselkin, 1993]. In addition, the telencephalon of lampreys appears to be only partially evaginated, such that the putative striatum and medial pallium remain part of an unevaginated telencephalon impar. Alternatively, what most observers have called the medial pallium (M? in Fig. 3) may be part of a very large prethalamic eminence [Pombal and Puelles, 1999; Pombal et al., 2009], in which case the medial pallium would be part of the evaginated pallium, which most authors call the lateral pallium. Most relevant to our present discussion is that one of us has previously identified a small dorsal pallium in lampreys [Northcutt and Puzdrowski, 1988] (D? in Fig. 3a, b), while others have doubted that lampreys possess this pallial division at all [Puelles, 2001].

Recent studies from the group of Sten Grillner (Fig. 3c, d) have shifted this debate in favor of the idea that lampreys do possess a dorsal pallium [Suryanarayana et al., 2020]. Specifically, they have shown that the dorsal part of what is traditionally called the lateral pallium in lampreys contains distinct visual and somatosensory areas, as well as an adjacent motor region with long descending projections [Ocaña et al., 2015; Suryanarayana et al., 2020]. On the basis of these findings, they suggested that "the basic sensorimotor representa- 
tion of the mammalian neocortex, as well as the sensory thalamocortical relay, had already evolved in the last common ancestor of cyclostomes and gnathostomes around 560 million years ago" [Suryanarayana et al., 2020, p. 639]. These data and interpretations are clearly at odds with our proposal, since they imply that the dorsal pallium is an ancient vertebrate structure and homologous across the extant vertebrates. Therefore, additional discussion is warranted.

One important question is whether the data of Grillner and colleagues contradict the earlier claims that the olfactory bulbs in lampreys project broadly throughout the pallium [Suryanarayana et al., 2020]. Suryanarayana et al. [2021] present neuroanatomical and physiological evidence that axons from the olfactory bulb terminate in what we call the ventral portion of the lateral pallium (L-v in Fig. 3a, b; their ventral pallium) and that this region then projects to the dorsal portion of the lateral pallium (L-d; their dorsal pallium). However, Suryanarayana et al. [2017] had previously shown that pallial neurons with long descending projections (many of which are located in the dorsal portion of the lateral pallium; Fig. 3c) respond monosynaptically to electrical stimulation of axons from the olfactory bulb. Thus, if these motor cortexlike neurons [Ocaña et al., 2015] represent part of a dorsal pallium, then this dorsal pallium receives secondary olfactory projections. Alternatively, the dorsal pallium in lampreys may be limited to the visual and somatosensory neurons that Suryanarayana et al. [2020] identified in the more medial portion of the dorsal lateral pallium. This region seems to receive few or no secondary olfactory projections [Northcutt and Puzdrowski, 1988], but it remains unclear whether the dendrites of the sensory cortex-like neurons in lampreys extend laterally into the olfactory bulb's pallial termination zone. In any case, physiological evidence that the visual or somatosensory neurons in the lamprey pallium do not respond to olfactory input have not, so far, been presented.

A second open question is whether the visual and somatosensory neurons in the lamprey pallium receive a direct thalamic input, as the dorsal pallium does in amniotes. Neuroanatomical data had previously indicated that the thalamus projects sparsely to much of the lamprey pallium (Fig. 3b) but projects most heavily to the medial pallium rather than the region identified by Grillner and colleagues as the dorsal pallium [Polenova and Vesselkin, 1993; Northcutt and Wicht, 1997; Suryanarayana et al., 2020]. Suryanarayana et al. [2017] did confirm through retrograde labeling that some thalamic neurons project to the lamprey's lateral pallium, and they provided physio- logical evidence for monosynaptic projections to the ventral division of the lateral pallium. However, the only published evidence for direct thalamic input to the visual and somatosensory areas in the lamprey pallium are illustrations of one neuron in the visually responsive region that extends a dendrite into a fiber tract that carries ascending thalamic axons (and, most likely, other axons) (Fig. 3d). It may seem reasonable to assume that visual and somatosensory information must reach the pallium via the thalamus, but as the data from ray-finned fishes have shown (see The Ray-Finned Fish Revolution), other routes are possible.

Third, we wonder whether the visual and somatosensory areas in the lamprey pallium could be part of what we would call the medial pallium or part of the lateral pallium rather than a distinct dorsal pallium. These suggestions may seem like definitional legerdemain but, as we mentioned previously, nonolfactory sensory representations are found in the lateral and medial pallial regions of teleosts (see The Ray-Finned Fish Revolution). Analogous ascending sensory projections to these pallial divisions may well exist in lampreys without requiring the presence of a dorsal pallium homologous to that of amniotes. Testing this hypothesis will probably require the discovery of transcription factors or other molecular markers that selectively label the embryonic medial or latera pallial divisions (including their dorsal portions) or the embryonic dorsal pallium in a variety of vertebrates, including anamniotes. We are not aware of any such markers. It is interesting to note, however, that the transcription factor $E m x$ duplicated independently in cyclostomes and jawed vertebrates, and that $e m \times B$ of lampreys is selectively expressed in the caudodorsal pole of the lamprey pallium [Tank et al., 2009]. Unfortunately, it remains unclear which adult brain areas correspond to this embryonic precursor region. Still, these data suggest that the lamprey pallium undergoes some lamprey- or cyclostome-specific differentiation that could, potentially, include the formation of a phylogenetically unique pallial zone.

Although the lamprey data require further elaboration and clarification, they should stimulate further research on nonolfactory sensory areas in the pallium of other anamniotes, even in species that exhibit widespread secondary olfactory projections. For example, it is already known that the pallium in hagfishes receives some minor and diffusely organized projections from the thalamus [Wicht and Northcutt, 1998], but it remains unclear whether the recipient pallial neurons also respond to olfactory stimuli. As noted earlier, it is entirely possible that the pallium 
Fig. 4. Evo-devo model of how dorsal pallia may emerge. a The diagrams depict a conceptually flattened forebrain, adapted from Puelles [2011] and Binks et al. [2019]. It shows that the dorsal pallium in amniotes develops as an island within the pallium and that pallial cell fates are specified by diffusible morphogenetic signals originating from the pallium's periphery (arrows with gradient shading). b Our suggestion that a dorsal pallium (DP) emerges whenever the embryonic pallium expands tangentially to such an extent that the morphogenetic signals specifying ventral, lateral, and medial pallial fates fail to reach the pallium's central region [Striedter and Northcutt, 2020]. We recently became aware that this basic idea was first proposed by Puelles [2001].
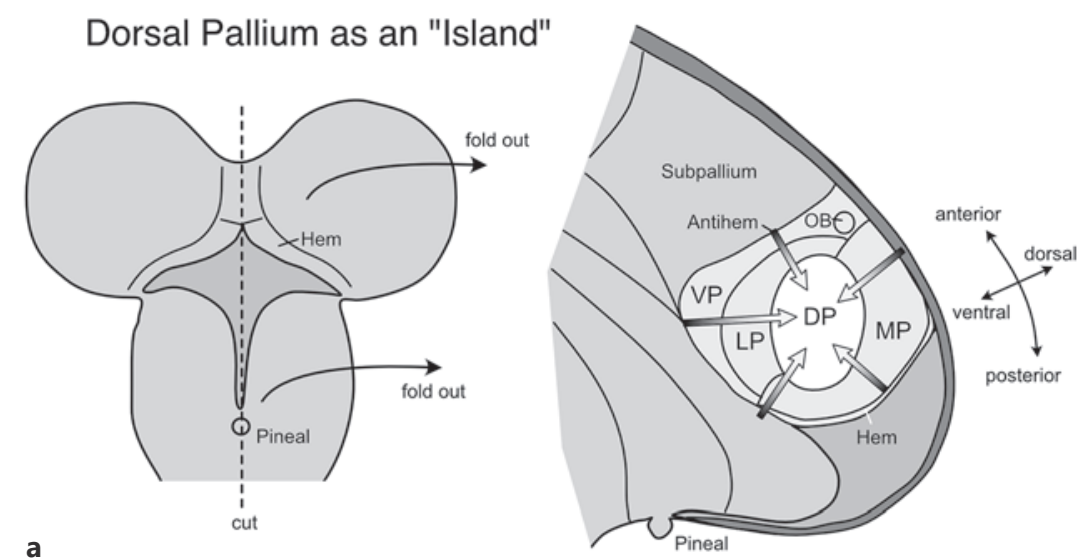

Emergence of a Dorsal Pallium
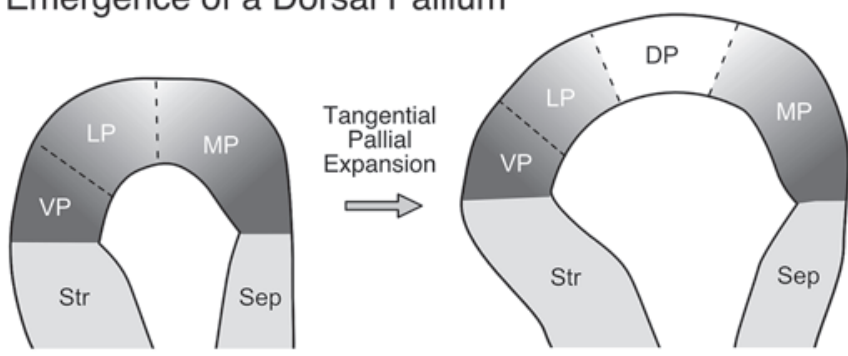

b of the earliest vertebrates received some nonolfactory inputs, but we hypothesize that the target neurons also received olfactory information.

\section{Our Model, Stated Succinctly}

Given these data and considerations, we now state our model of dorsal pallial evolution as three interrelated hypotheses: (1) secondary olfactory projections to the pallium were widespread in the earliest vertebrates, covering most or all of the pallium, but then receded in several vertebrate lineages; (2) pallial territory that became devoid of secondary olfactory projections was "invaded" by additional ascending nonolfactory sensory inputs, which were conveyed through the thalamus or other lower brain regions; and (3) as the pallium expanded in some vertebrate lineages, a novel pallial zone appeared in the pallium's central region, in between the medial and lateral pallia and far from signaling centers along the pallium's periphery (Fig. 4). These dorsal pallial regions may or may not coincide with the nonolfactory sensory regions but are, in any case, not homologous across all vertebrates.

We are not the first to argue in favor of these, or very similar, hypotheses. The smell brain hypothesis was developed by an earlier generation of comparative neuroanatomists (see Previous Ideas about Pallial Evolution), and Wullimann and Vernier [2009] clearly stated that "a dorsal pallium may have arisen several times independently in chondrichthyans (i.e., cartilaginous fishes), teleosts and amniotes." Doubts about the existence of a dorsal pallium homolog in various anamniotes, as well as an evo-devo scenario for its emergence, have also been expressed before [Puelles, 2001; Holmes and Northcutt, 2003]. Still, we had not anticipated reaching these conclusions when we began writing our book and, therefore, would argue that they are not widely considered or, certainly, accepted in the field.

More important than establishing priority is to determine what kinds of data would allow for tests of the proposed hypotheses. Regarding our first hypothesis, it will be important to complement neuroanatomical data on 
the distribution of secondary olfactory projections in various anamniotes with physiological data. Specifically, we need to know which neurons respond to olfactory inputs and which do not. Similarly, testing our second hypothesis will require data from multiple anamniotes and the integration of neuroanatomical and physiological data, with a special emphasis on the pathways through which nonolfactory sensory information reaches the pallium. Our third hypothesis appears most difficult to test. A good first step would be to identify molecular markers for the embryonic dorsal pallium in anamniotes that are thought to possess a dorsal pallium and then to determine whether similar expression patterns are found in other vertebrates, including amniotes [Desfilis et al., 2018]. It might also be possible to manipulate the size of the embryonic pallium to see whether experimental expansion causes novel brain regions to emerge (Fig. 4) or, conversely, whether experimental reductions in pallium size cause putative dorsal pallia to disappear. Combining such evodevo experiments with manipulations of the olfactory inputs to the developing pallium might also yield results relevant to our proposal.

We freely admit that the hypotheses presented here are risky (as one reviewer put it), because they are not supported by extensive evidence and run counter to ideas currently predominant within comparative neuroanatomy. Indeed, we have some doubts ourselves. Still, we believe that the ideas are worth considering and testing thoroughly. In that sense, we share the view of Darwin [1871, p. 385] that, "false facts are highly injurious to the progress of science, for they often long endure; but false views, if supported by some evidence, do little harm, for everyone takes a salutary pleasure in proving their falseness."

\section{Conclusion}

Most comparative neurobiologists, including the two of us, had been assuming that the pallium of all vertebrates conforms to an ancient Bauplan. Specifically, we used to think that the pallium's division into 4 fundamental zones would be conserved across all vertebrates and that, therefore, all vertebrates should possess some kind of dorsal pallium. Once we dropped this assumption, the evidence for a dorsal pallium that is homologous across all vertebrates appeared (to us) surprisingly weak. This realization prompted us to think more deeply about alternative scenarios of pallial evolution.

It can be difficult to imagine how a novel brain region, such as a dorsal pallium, can possibly appear "from noth- ing" in evolution [Ebbesson, 1980]. Indeed, "morphological structures, and the ontogenies which produce them, do not simply arise from the dust of the earth" [Braun and Northcutt, 1997, p. 263]. However, novel entities certainly can arise in evolution. They do so when ontogenies are modified in such a way that developmental factors are combined in novel ways and, thereby, specify new, additional traits (rather than slightly modifying old ones). Such evolutionary innovations can be difficult to identify with certainty, since one must demonstrate the absence of suitable ancestral homologs, and their developmental bases are likewise difficult to uncover [e.g., see Shigetani et al., 2005]. However, one can certainly imagine, as we have done (Fig. $4 \mathrm{~b}$ ), speculative scenarios that generate true novelties [see also Puelles, 2001].

An interesting implication of our model is that dorsal pallia may have arisen independently in several vertebrate lineages via shared developmental mechanisms, i.e., tangential expansion of the embryonic pallium and its knock-on effects. Because of those shared mechanisms, the independently evolved dorsal pallia may share some adult characteristics (e.g., their topological position between the medial and lateral pallia and the presence of nonolfactory sensory inputs) that are suggestive of homology but are actually the result of parallel evolution [Hall, 2003]. General considerations of this type have given rise to the concept of "developmental homology" [DiFrisco, 2019] but, to our way of thinking, homology requires that the traits being compared can be traced back - via a continuous evolutionary history - to a common ancestral trait [Striedter and Northcutt, 1991; Striedter, 1998]. This would not be the case in the scenario we have proposed.

\section{Acknowledgment}

We greatly appreciate the opportunity to contribute to this Special Issue honoring Luis Puelles and Agustín González. We have known them for a long time and always enjoyed their scholarship and company; few have contributed as much to the advancement of their field. We are also grateful to Mario Wullimann and Nerea Moreno García for feedback on our manuscript. Of course, they should not be blamed if you find fault with our hypotheses.

\section{Conflict of Interest Statement}

The authors have no conflict of interests to declare. 


\section{Funding Sources}

There are no funding sources to declare.

\section{Author Contributions}

Both authors made essential contributions to this work.

\section{References}

Binks D, Watson C, Puelles L. A Re-evaluation of the anatomy of the claustrum in rodents and primates: analyzing the effect of pallial expansion. Front Neuroanat. 2019 Mar; 13:34.

Bloch S, Hagio H, Thomas M, Heuzé A, Hermel JM, Lasserre E, et al. Non-thalamic origin of zebrafish sensory nuclei implies convergent evolution of visual pathways in amniotes and teleosts. eLife. 2020 Sep;9:e54945.

Bodznick D. Elasmobranch vision: multimodal integration in the brain. J Exp Zool Suppl. 1990;5:108-16.

Bodznick D, Northcutt RG. An electrosensory area in the telencephalon of the little skate, Rajaerinacea.Brain Res.1984Apr;298(1):11724.

Bohm D. Causality and Chance in Modern Physics. Philadelphia: U Penn Press; 1957.

Bolker JA. Selection of models: evolution and the choice of species for translational research. Brain Behav Evol. 2019;93(2-3):82-91.

Braford MR Jr. Stalking the everted telencephalon: comparisons of forebrain organization in basal ray-finned fishes and teleosts. Brain Behav Evol. 2009;74(1):56-76.

Braun CB, Northcutt RG. The lateral line system of hagfishes (Craniata: myxinoidea). Acta Zool. 1997;78(3):247-68.

Butler AB, Hodos W. Comparative Vertebrate Neuroanatomy. Hoboken (NJ): Wiley; 2005. https://doi.org/10.1002/0471733849.

Darwin CR. The Descent of Man, and Selection in Relation to Sex. Volume 2. London: Murray; 1871.

Demski LS. The pallium and mind/behavior relationships in teleost fishes. Brain Behav Evol. 2013;82(1):31-44.

Desfilis E, Abellán A, Sentandreu V, Medina L. Expression of regulatory genes in the embryonic brain of a lizard and implications for understanding pallial organization and evolution. J Comp Neurol. 2018 Jan;526(1):166202.

DiFrisco J. Developmental homology. In: Nuno de la Rosa L, Müller G, editors. Evolutionary Developmental Biology. Cham: Springer; 2019. pp. 1-13.

Ebbesson SO. The parcellation theory and its relation to interspecific variability in brain organization, evolutionary and ontogenetic development, and neuronal plasticity. Cell Tissue Res. 1980;213(2):179-212.

Ebbesson SO, Heimer L. Projections of the olfactory tract fibers in the nurse shark (Ginglymostoma cirratum). Brain Res. 1970 Jan;17(1):4755.

Ebbesson SO, Schroeder DM. Connections of the nurse shark's telencephalon. Science. 1971 Jul;173(3993):254-6.
Fernandez AS, Pieau C, Repérant J, Boncinelli E, Wassef M. Expression of the Emx-1 and Dlx1 homeobox genes define three molecularly distinct domains in the telencephalon of mouse, chick, turtle and frog embryos: implications for the evolution of telencephalic subdivisions in amniotes. Development. 1998 Jun;125(11):2099-111.

Friedmann HC. From "butyribacterium" to "E. coli": an essay on unity in biochemistry. Perspect Biol Med. 2004;47(1):47-66.

González A, Northcutt RG. An immunohistochemical approach to lungfish telencephalic organization. Brain Behav Evol. 2009;74(1):43-55.

Hall BK. Descent with modification: the unity underlying homology and homoplasy as seen through an analysis of development and evolution. Biol Rev Camb Philos Soc. 2003 Aug;78(3):409-33.

Harvey-Girard E, Giassi AC, Ellis W, Maler L. Organization of the gymnotiform fish pallium in relation to learning and memory: IV. Expression of conserved transcription factors and implications for the evolution of dorsal telencephalon. J Comp Neurol. 2012 Oct;520(15):3395-413.

Hofmann MH, Northcutt RG. Organization of major telencephalic pathways in an elasmobranch, the thornback ray Platyrhinoidis triseriata. Brain Behav Evol. 2008;72(4):307-25.

Hofmann MH, Northcutt RG. Forebrain organization in elasmobranchs. Brain Behav Evol. 2012;80(2):142-51.

Holmes PH, Northcutt RG. Connections of the pallial telencephalon in the Senegal bichir, Polypterus. Brain BehavEvol.2003;61(3):11347.

Kanwal JS, Finger TE, Caprio J. Forebrain connections of the gustatory system in ictalurid catfishes. J Comp Neurol. 1988 Dec;278(3):353-76.

Krell FT, Cranston PS. Which side of the tree is more basal? Syst Entomol. 2004;29(3):279-81.

Luiten PG. Two visual pathways to the telencephalon in the nurse shark (Ginglymostoma cirratum). I. Retinal projections. J Comp Neurol. 1981 Mar;196(4):531-8.

Maslin TP. Morphological criteria of phyletic relationships. Syst Zool. 1952;1(2):49-70.

Medina L, Legaz I, González G, De Castro F, Rubenstein JL, Puelles L. Expression of Dbx1, Neurogenin 2, Semaphorin 5A, Cadherin 8, and Emxl distinguish ventral and lateral pallial histogenetic divisions in the developing mouse claustroamygdaloid complex. J Comp Neurol. 2004 Jul;474(4):504-23.
Mueller T, Dong Z, Berberoglu MA, Guo S. The dorsal pallium in zebrafish, Danio rerio (Cyprinidae, Teleostei). Brain Res. 2011 Mar;1381:95-105.

Murakami T, Morita Y, Ito H. Extrinsic and intrinsic fiber connections of the telencephalon in a teleost, Sebastiscus marmoratus. J Comp Neurol. 1983 May;216(2):115-31.

Neary TJ. The pallium of anuran amphibians. In: Jones EG, Peters A, editors. Comparative structure and evolution of the cerebral cortex: Part I. Cerebral cortex. Boston: Springer; 1990. p. 107-38.

Nieuwenhuys R. The comparative anatomy of the actinopterygian forebrain. J Hirnforsch. 1963;7:171-92.

Nieuwenhuys R. The forebrain of actinopterygians revisited. Brain Behav Evol. 2009;73(4):229-52.

Northcutt RG. Evolution of the telencephalon in nonmammals. Annu Rev Neurosci. 1981;4(1):301-50.

Northcutt RG. The forebrain of gnathostomes: in search of a morphotype. Brain Behav Evol. 1995;46(4-5):275-318.

Northcutt RG. Telencephalic organization in the spotted African Lungfish, Protopterus dolloi: a new cytological model. Brain Behav Evol. 2009;73(1):59-80.

Northcutt RG. Olfactory projections in the white sturgeon, Acipenser transmontanus: an experimental study. J Comp Neurol. 2011 Jul;519(10):1999-2022.

Northcutt RG, Braford MR. New observations on the organization and evolution of the telencephalon of actinopterygian fishes. In: Ebbesson SO, editor. Comparative Neurology of the Telencephalon. Boston: Springer; 1980. pp. 41-98.

Northcutt RG, Davis RE. Telencephalic organization in ray-finned fishes. In: Northcutt RG, Davis RE, editors. Fish Neurobiology. Ann Arbor: U Michigan Press; 1983. pp. 203-36.

Northcutt RG, Puzdrowski RL. Projections of the olfactory bulb and nervus terminalis in the silver lamprey. Brain Behav Evol. 1988;32(2):96107.

Northcutt RG, Rink E. Olfactory projections in the lepidosirenid lungfishes. Brain Behav Evol. 2012;79(1):4-25.

Northcutt RG, Royce GJ. Olfactory bulb projections in the bullfrog Rana catesbeiana. J Morphol. 1975 Mar;145(3):251-67.

Northcutt RG, Wicht H. Afferent and efferent connections of the lateral and medial pallia of the silver lamprey. Brain Behav Evol. 1997;49(1):1-19. 
Ocaña F, Gómez A, Durán E, Monzón M, Trujillo I, Broglioa C, et al. Voltage-sensitive dye imaging reveals segregated sensory areas and topographic maps in the goldfish pallium. In : Abstract Book: 8th European Conference on Comparative Neurobiology. Munich; 2016. p. 47.

Ocaña FM, Suryanarayana SM, Saitoh K, Kardamakis AA, Capantini L, Robertson B, et al. The lamprey pallium provides a blueprint of the mammalian motor projections from cortex. Curr Biol. 2015 Feb;25(4):413-23.

Polenova OA, Vesselkin NP. Olfactory and nonolfactory projections in the river lamprey (Lampetra fluviatilis) telencephalon. J Hirnforsch. 1993;34(2):261-79.

Pombal MA, Megías M, Bardet SM, Puelles L. New and old thoughts on the segmental organization of the forebrain in lampreys. Brain Behav Evol. 2009;74(1):7-19.

Pombal MA, Puelles L. Prosomeric map of the lamprey forebrain based on calretinin immunocytochemistry, Nissl stain, and ancillary markers. J Comp Neurol. 1999 Nov;414(3):391-422.

Porter BA, Mueller T. The zebrafish amygdaloid complex: functional ground plan, molecular delineation, and everted topology. Front Neurosci. 2020 Jul;14:608.

Puelles L. Thoughts on the development, structure and evolution of the mammalian and avian telencephalic pallium. Philos Trans R Soc Lond B Biol Sci. 2001 Oct;356(1414):1583-98.

Puelles L. Pallio-pallial tangential migrations and growth signaling: new scenario for cortical evolution? Brain Behav Evol. 2011;78(1):10827.

Puelles L. Comments on the updated tetrapartite pallium model in the mouse and chick, featuring a homologous claustro-insular complex. Brain Behav Evol. 2017;90(2):171-89.

Puelles L, Kuwana E, Puelles E, Bulfone A, Shimamura K, Keleher J, et al. Pallial and subpallial derivatives in the embryonic chick and mouse telencephalon, traced by the expression of the genes Dlx-2, Emx-1, Nkx-2.1, Pax6, and Tbr-1. J Comp Neurol. 2000 Aug;424(3):409-38

Puelles L, Medina L, Borello U, Legaz I, Teissier A, Pierani A, et al. Radial derivatives of the mouse ventral pallium traced with Dbx1LacZ reporters. J Chem Neuroanat. 2016 Sep;75:2-19.

Puelles L, Sandoval JE, Ayad A, del Corral R, Alonso A, Ferran JL, et al. The pallium in reptiles and birds in the light of the updated tetrapartite pallium model. In: Kaas J, Striedter GF, editors. Evolution of Nervous Systems.
Volume 1. 2nd ed. Amsterdam: Elsevier; 2017. pp. 519-55.

Rodríguez F, López JC, Vargas JP, Gómez Y, Broglio C, Salas C. Conservation of spatial memory function in the pallial forebrain of reptiles and ray-finned fishes. J Neurosci. 2002 Apr;22(7):2894-903.

Saidel WM, Marquez-Houston K, Butler AB. Identification of visual pallial telencephalon in the goldfish, Carassius auratus: a combined cytochrome oxidase and electrophysiological study. Brain Res. 2001 Nov;919(1):82-93.

Scalia F, Ebbesson SO. The central projections of the olfactory bulb in a teleost (Gymnothorax funebris). Brain Behav Evol. 1971;4(5):37699.

Shigetani Y, Sugahara F, Kuratani S. A new evolutionary scenario for the vertebrate jaw. BioEssays. 2005 Mar;27(3):331-8.

Smeets W, Nieuwenhuys R, Roberts BL. The Central Nervous System of Cartilaginous Fishes. Berlin: Springer; 2011.

Smeets WJ, Northcutt RG. At least one thalamotelencephalic pathway in cartilaginous fishes projects to the medial pallium. Neurosci Lett. 1987 Aug;78(3):277-82.

Striedter GF. Auditory, electrosensory, and mechanosensory lateral line pathways through the forebrain in channel catfishes. J Comp Neurol. 1991 Oct;312(2):311-31.

Striedter GF. The telencephalon of tetrapods in evolution. Brain Behav Evol. 1997;49(4):179213.

Striedter GF. Stepping into the same river twice: homologues as recurring attractors in epigenetic landscapes. Brain Behav Evol. 1998;52(45):218-31.

Striedter GF. Variation across species and levels: implications for model species research. Brain Behav Evol. 2019;93(2-3):57-69.

Striedter GF, Northcutt RG. Biological hierarchies and the concept of homology. Brain Behav Evol. 1991;38(4-5):177-89.

Striedter GF, Northcutt RG. Brains Through Time: A Natural History of Vertebrates. New York: Oxford University Press; 2020.

Suryanarayana SM, Pérez-Fernández J, Robertson B, Grillner S. The evolutionary origin of visual and somatosensory representation in the vertebrate pallium. Nat Ecol Evol. 2020 Apr;4(4):639-51.

Suryanarayana SM, Pérez-Fernández J, Robertson B, Grillner S. Olfaction in Lamprey Pallium Revisited-Dual Projections of Mitral and Tufted Cells. Cell Rep. 2021 Jan;34(1): 108596.

Suryanarayana SM, Robertson B, Wallén P, Grillner $\mathrm{S}$. The lamprey pallium provides a blue- print of the mammalian layered cortex. Curr Biol. 2017 Nov;27(21):3264-3277.e5.

Tank EM, Dekker RG, Beauchamp K, Wilson KA, Boehmke AE, Langeland JA. Patterns and consequences of vertebrate Emx gene duplications. Evol Dev. 2009 Jul-Aug;11(4):343-53.

von Bartheld CS, Meyer DL. Central connections of the olfactory bulb in the bichir, Polypterus palmas, reexamined. Cell Tissue Res. 1986;244(3):527-35.

von der Emde G, Prechtl JC. Anatomical connections of auditory and lateral line areas of the dorsal telencephalon $(\mathrm{Dm})$ in the osteoglossomorph teleost, Gnathonemus petersii. Brain Res. 1999 Feb;818(2):355-67.

Wicht H, Northcutt RG. The forebrain of the Pacific hagfish: a cladistic reconstruction of the ancestral craniate forebrain. Brain Behav Evol. 1992;40(1):25-64.

Wicht H, Northcutt RG. Secondary olfactory projections and pallial topography in the Pacific hagfish, Eptatretus stouti. J Comp Neurol. 1993 Nov;337(4):529-42.

Wicht H, Northcutt RG. Telencephalic connections in the Pacific hagfish (Eptatretus stouti), with special reference to the thalamopallial system. J Comp Neurol. 1998 Jun;395(2):24560.

Wullimann MF. Nervous system architecture in vertebrates. In: Shepherd SV, editor. The Wiley Handbook of Evolutionary Neuroscience. New York: Wiley; 2017a. pp. 236-78.

Wullimann MF. Should we redefine the classic lateral pallium? J Comp Neurol. 2017b Apr;525(6):1509-13.

Wullimann MF. Neural origins of basal diencephalon in teleost fishes: radial versus tangential migration. J Morphol. 2020 Sep;281(9):113341.

Wullimann MF, Grothe B. The central nervous organization of the lateral line system. In: Coombs S, Bleckmann H, Fay RR, Popper AN, editors. The Lateral Line System. New York: Springer; 2013. pp. 195-251.

Wullimann MF, Mueller T. Teleostean and mammalian forebrains contrasted: evidence from genes to behavior. J Comp Neurol. 2004 Jul;475(2):143-62.

Wullimann MF, Vernier P. Evolution of the telencephalon in anamniotes [Internet]. In: Binder MD, Hirokawa N, Windhorst U, editors. Encyclopedia of Neuroscience. Berlin: Springer; 2009. pp. 1424-31.

Yamamoto N, Ito H. Visual, lateral line, and auditory ascending pathways to the dorsal telencephalic area through the rostrolateral region of the lateral preglomerular nucleus in cyprinids. J Comp Neurol. 2008 Jun;508(4):615-47. 